\title{
The Measurement and Uncertainty Analysis of Antenna Factor of Microwave Antennas Based on Standard Site Method
}

\author{
Chaochan Chen, Hong Shi, Yi Miao, Yu Sang \\ Shanghai Institution of Measurement and Testing Technology, Shanghai, China \\ Email: chencc@simt.com.cn, shih@simt.com.cn,miaoy@simt.com.cn, sangy@simt.com.cn
}

How to cite this paper: Chen, C.C., Shi, H., Miao, Y. and Sang, Y. (2017) The Measurement and Uncertainty Analysis of Antenna Factor of Microwave Antennas Based on Standard Site Method. Int. J. Communications, Network and System Sciences, 10, 138-145.

https://doi.org/10.4236/ijcns.2017.105B013

Received: March 25, 2017

Accepted: May 23, 2017

Published: May 26, 2017

\begin{abstract}
A method of Standard Site Method (SSM) in the American National Standards Institute's ANSI C63.5 is de-scribed in the frequency ranges from 30 $\mathrm{MHz}$ to $1000 \mathrm{MHz}$. And a measurement system is set up for determining antenna factors (AF) of antennas on an Open Area Test Sites (OATS). AF of antennas including log-periodic antenna and biconical antenna is measured with SSM method by Shanghai Institute of Measurement and Testing Technology (SIMT), which shows good agreement to data measured by National Institute of Metrology (NIM). In the end, it analyzes the measurement uncertainty of SIMT in the $30 \mathrm{MHz}$ to $1000 \mathrm{MHz}$ frequency band and does comparison to that of NIM.
\end{abstract}

\section{Keywords}

Antenna Factors, Standard Site Method (SSM) Measurement Uncertainty

\section{Introduction}

High growth in the electromagnetic compatibility (EMC) field makes antennas absolutely important part in EMC test. There are two reasons below:

1) EMC test need: Antennas are used in many key EMC tests, antenna factors (AF) determined is a major work in making field strength measurements accurate for EMC compliance. For example, in the electromagnetic radiation disturbance test, we use antennas to receive the interference noise and transfer it to EMI receiver through coaxial cable.

2) Site validation need: Antennas are used to validate the performance of test sites such as Open Area Test Sites (OATS) and anechoic chambers, by measuring the parameter of normalized site attenuation (NSA) with ANSI C63.4 standard. 
We can find out that the performance of the antennas affects the test results, accurate measurement and traceability of antennas are both important to EMC test. The measurement methods are prescribed in standards such as those published by the ANSI and CISPR [1]-[6]. Three commonly used measurement methods used to calibrate the AF are Reference Antenna Method (RAM), Equivalent Capacitance Substitute Method (ECSM) and Standard Site Method (SSM). These methods' advantages and limitations are illustrated clearly in many papers.

ECSM is used to calibrate AF of monopole antennas frequency ranges from 9 $\mathrm{kHz}$ to $30 \mathrm{MHz}$ according to standard ANSI C63.5-2003. RAM provide an AF measurement method based on the use of dipole with well-matched balun in 30 $\mathrm{kHz}$ to $1000 \mathrm{MHz}$. SSM is the most used method to measure AF parameter from $30 \mathrm{MHz}$ to $1000 \mathrm{MHz}$. This paper provides the setup of SSM test system on OATS in Zhejiang Province of China.

\section{AF Measurement Technique OF SSM}

\subsection{Definition of Antenna Factor (AF)}

Antenna factor (AF) is probably is the most important concern of parameter to determine the Antennas used in EMC field. According to ANSI C63.5, AF can be defined as ratio of the electric field in the polarization direction of the antenna to the voltage induced across the load connected to the antenna and expressed in decibel form $(20 \log (\mathrm{E} / \mathrm{Vo}))$.

\subsection{Principles of SSM}

Standard Site Method (SSM) is well described for determining antenna performance in some standards [1]-[5].

The SSM requires three site attenuation measurements under identical geometries $\left(h_{1}, h_{2}, R\right)$ using three different antennas taken in pairs, as shown in Figure 1 . The three equations associated with the three site attenuation measurements are Equation (1), Equation (2), and Equation (3).

$$
\begin{aligned}
& A F_{1}=10 \log f_{M}-24.46+1 / 2\left(E_{D}^{\max }+A_{1}+A_{2}-A_{3}\right) \\
& A F_{2}=10 \log f_{M}-24.46+1 / 2\left(E_{D}^{\max }+A_{1}+A_{3}-A_{2}\right) \\
& A F_{3}=10 \log f_{M}-24.46+1 / 2\left(E_{D}^{\max }+A_{2}+A_{3}-A_{1}\right)
\end{aligned}
$$

where:

$E_{D}^{\max }$ is the maximum received field at separation distance R from the transmitting antenna.

$A F_{1}, A F_{2}, A F_{3}$ are the antenna factors of antennas $1,2,3 \mathrm{in} \mathrm{dB}(1 / \mathrm{m})$.

$A_{1}$ is the measured site attenuation in $\mathrm{dB}$ using antenna 1 and 2 .

$A_{2}$ is the measured site attenuation in $\mathrm{dB}$ using antenna 1 and 3.

$A_{3}$ is the measured site attenuation in $\mathrm{dB}$ using antenna 2 and 3.

$f_{\mathrm{M}}$ is the frequency in $\mathrm{MHz}$.

The model assumes a separation of $10 \mathrm{~m}(\mathrm{R})$ between the antennas. SSM me- 


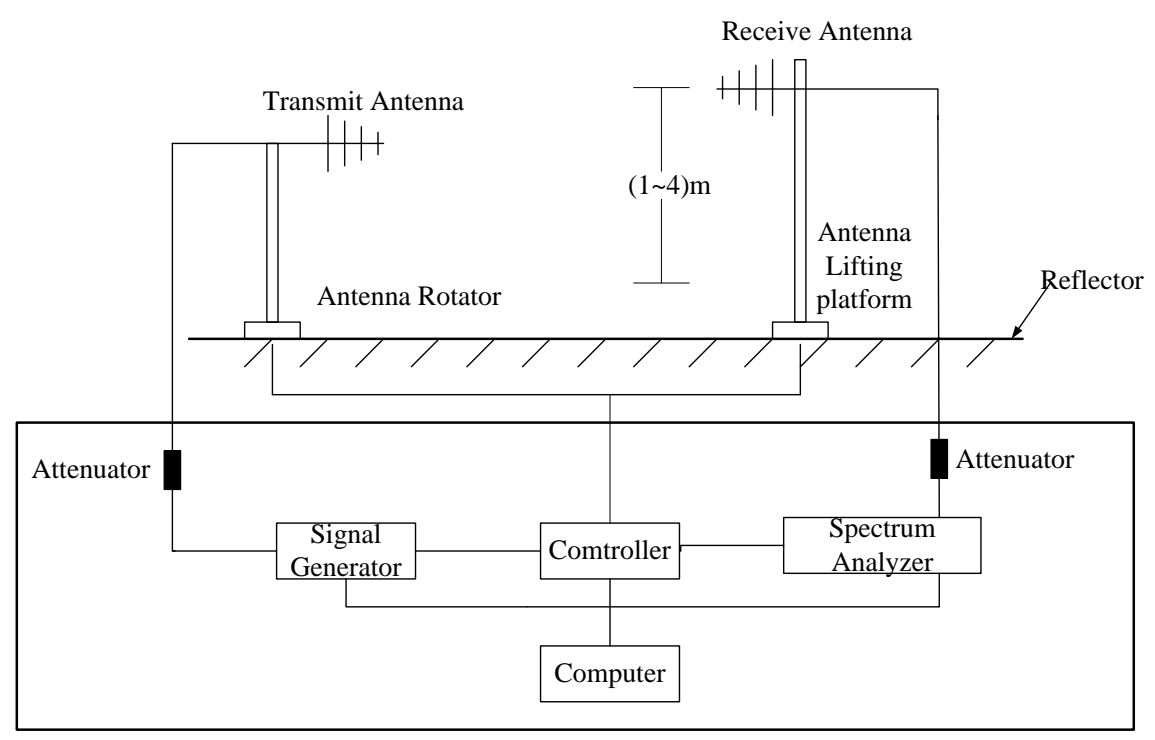

Figure 1. AF measurement system.

thod (based solely on horizontally polarized measurements) provides AF measurements from $30 \mathrm{MHz}$ to $1000 \mathrm{MHz}$. The measurement method is the same in both cases. The distance between two antennas is $10 \mathrm{~m}$, the height of transmitting antenna is $2 \mathrm{~m}$ and the receiving antenna is mounted on bracket, shifting the height from $1 \mathrm{~m}$ to $4 \mathrm{~m}$ and scanning the maximum power.

These dimensions are annotated in Table 2, which provides values for $\mathrm{ED}_{\max }$ and ideal site attenuation (SA) (Figure 1 provides the measurement sketch). Antenna factors shall be determined only for horizontal polarization on a standard antenna calibration site, hereafter referred to as a standard site, using the SSM. Horizontal polarization measurements are relatively insensitive to site variations and yield acceptable antenna factors even though the reflecting plane does not create a free-space environment during calibration.

\section{AF Measurement of Antennas}

In this paper, we adopt SSM method for the calibration of antennas obtained by the C63.5 procedure. To satisfy our own calibration condition, we establish a test system, which was shown in Figure 2. It consists of computer, frequency method, signal generator, spectrum analyzer, antenna amounting bracket and its controller. Here we choose discrete frequencies.

For AF measurement experiments, standard biconical antennas and log-periodic antennas of Shanghai Institution of Measurement and Testing Technology (SIMT) are achieved on OATS in Zhejiang province as Figure 2 shows. Their specifications are shown in Table 1 and Table 2. To ensure the accuracy and reliability of the test, the AF data of standard antennas are also calibrated by the National institute of metrology on OATS.

We get the insertion loss (IL) of different frequency points with spectrum analyzer, and calculate AF data according to Formula (1) to Formula (3). By analyzing the above equations, $\mathrm{AF}$ is related to site attenuation and the maxi- 


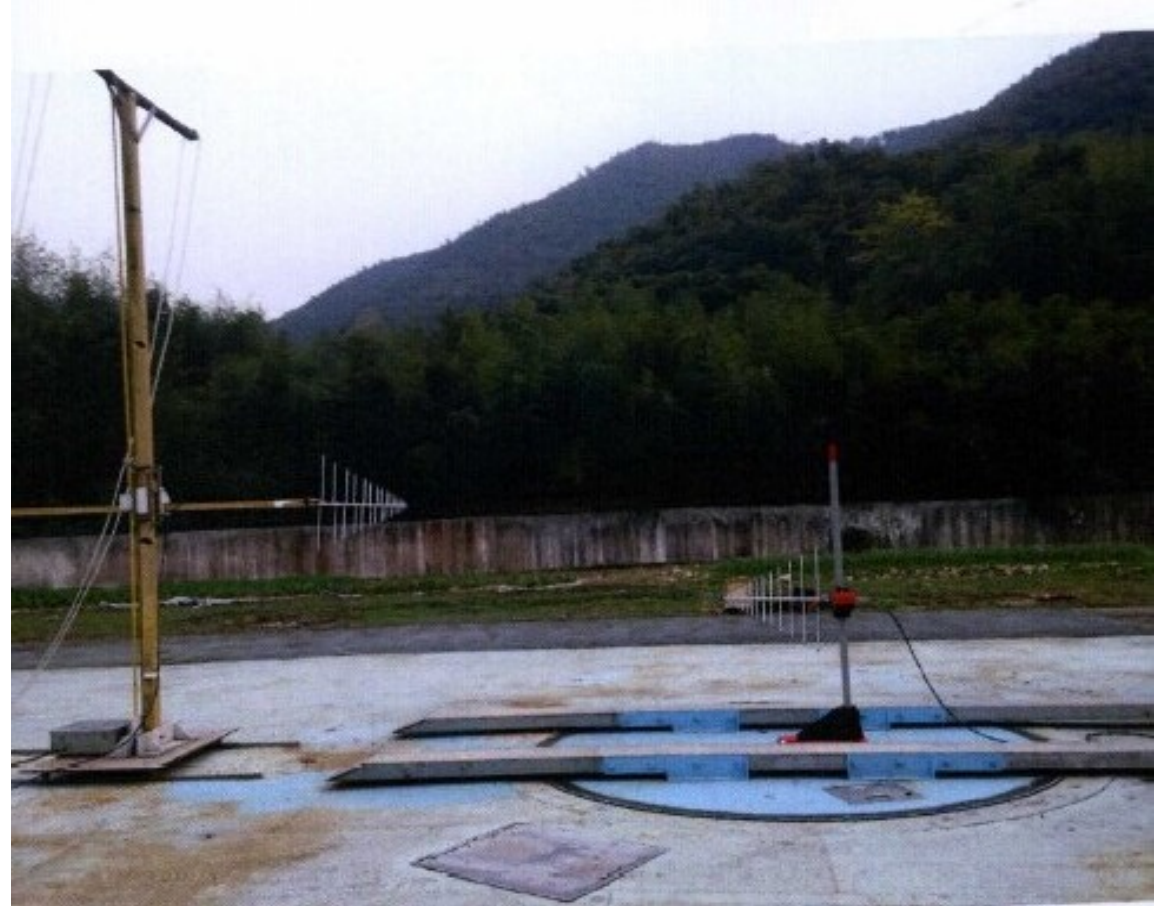

Figure 2. AF measurement system on OATS.

Table 1. Type of biconical antennas.

\begin{tabular}{ccccc}
\hline $\mathrm{AF}_{\mathrm{n}}$ & Antennas & Model & Serials & Polarization \\
\hline $\mathrm{AF}_{1}$ & biconical antenna & $\mathrm{HK} 116$ & 100,183 & horizontal \\
$\mathrm{AF}_{2}$ & biconical antenna & $\mathrm{HK} 116$ & 100,182 & horizontal \\
$\mathrm{AF}_{3}$ & composite log-periodic antenna & 3134 & $9803-1092$ & horizontal \\
\hline
\end{tabular}

Table 2. Type of log periodic antennas.

\begin{tabular}{ccccc}
\hline $\mathrm{AF}_{\mathrm{n}}$ & Antennas & Model & Serials & Polarization \\
\hline $\mathrm{AF}_{1}$ & $\begin{array}{c}\text { composite } \\
\text { log-periodic antenna }\end{array}$ & 3134 & $9803-1092$ & horizontal \\
$\mathrm{AF}_{2}$ & log-periodic antenna & HL223 & 100,182 & horizontal \\
$\mathrm{AF}_{3}$ & log-periodic antenna & HL223 & 100,183 & horizontal \\
\hline
\end{tabular}

mum received field at separation distance. Figure 3 presents the AF curves of two biconical antennas measured by SIMT and National Institute of Metrology (NIM) and Figure 4 presents the AF curves of two log periodic antennas measured by SIMT and NIM separately.

Both curves obtained by SIMT and NIM keep in consistent at desired frequency ranges. Now we focus on the comparison between two testing organizations for two different antennas respectively.

Figure 3 indicates that there are certain differences of data measured by SIMT and NIM, especially in the frequency range from $80 \mathrm{MHz}$ to $90 \mathrm{MHz}$. One of the most important reasons is that as a representative EMC antenna, biconical antenna has lower frequencies (range from $30 \mathrm{MHz}$ to $300 \mathrm{MHz}$ ), so it is difficult 
to eliminate the influence of the OATS' ground, so we should make sure that the floor is well conductive before test.

Figure 4 shows apparently that AF data measured by SIMT is higher than that of NIM. We should consider the mutual coupling between two antennas at $10 \mathrm{~m}$ distance. Besides of that, antennas are affected by different measurement system and equipments, OATS is an important influencing factor that cannot be neglected.

\section{Estimation of Measurement Uncertainty}

In the process of calibrated AF parameter, we should consider the uncertainty caused by measurement instruments and the factors of antenna coupling and OATS.

In metrology, measurement uncertainty is a parameter characterizing the dispersion of the values attributed to a measured quantity [7]. For antenna calibration, the measurement must include the uncertainty components, taking into consideration the environment in which the antenna is to be used for the testing.

The AF measurement process includes a spectrum analyzer, signal generator, amplifier, cables, attenuators, OATS. All these issues should be taken into ac-

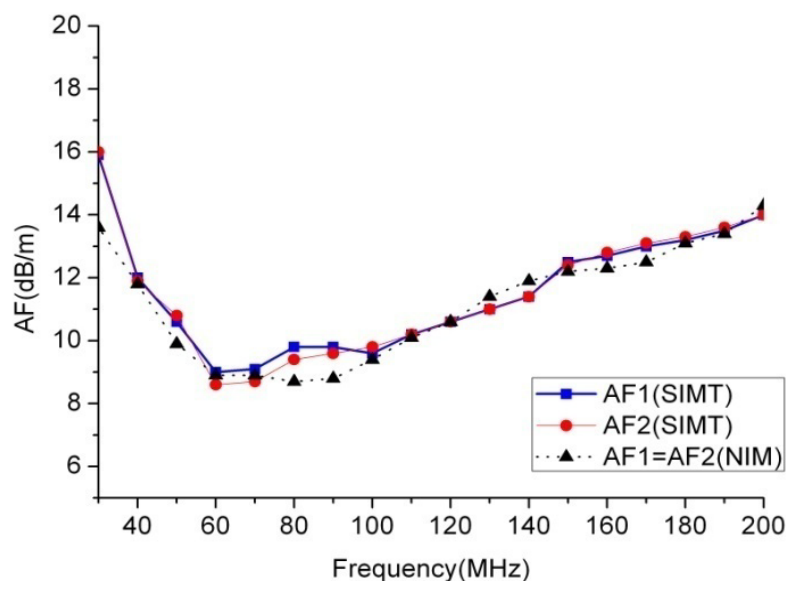

Figure 3. AF of biconical antennas calibrated.

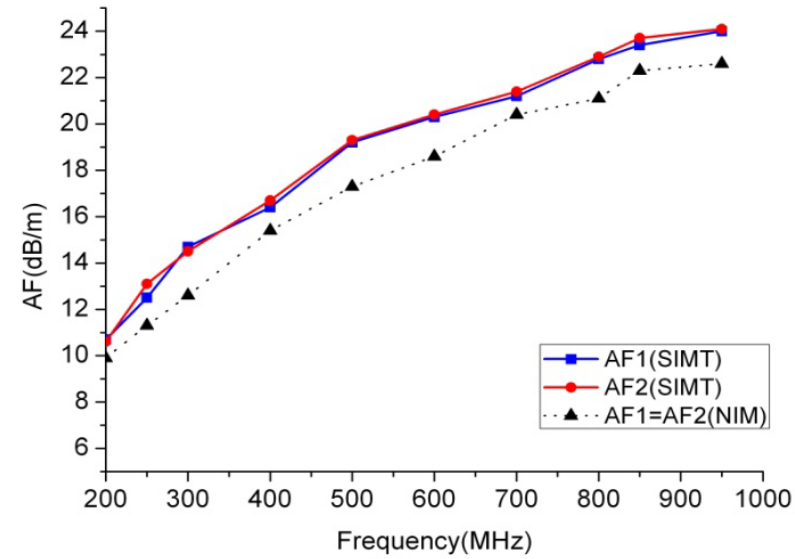

Figure 4. AF of log-periodic antennas calibrated. 
count in the uncertainties determination. The contribution to measurement uncertainty from the system can be determined by using type A evaluation and other contribution can be determined by using type B evaluation.

Considering the uncertainty of AF measurement for log periodic antennas, here we discuss standard uncertainty components to each factor respectively.

1) Spectrum analyzers factor. Spectrum analyzers have two primary sources of uncertainty that shall be considered with respect to the calibration procedure. These sources are frequency accuracy, and amplitude accuracy. The influence of frequency accuracy can be ignored with respect to amplitude accuracy. So in the frequency range from $200 \mathrm{MHz}$ to $1000 \mathrm{MHz}$, we get the uncertainty component:

$$
U_{A}^{S A}=0.3+30 * 0.01 / 10=0.6 \mathrm{~dB}
$$

2) Signal generator factor. The amplitude uncertainty contribution $U_{A}^{S A}$ based on the amplitude stability is:

$$
U_{A}^{S A}=0.1 \mathrm{~dB}
$$

3) Impedance mismatch of Spectrum analyzer and antenna: In the frequency band of $200 \mathrm{MHz}-1000 \mathrm{MHz}$, VSWR of antenna (connected with 6dB attenuator) is 1.2 and that of Spectrum analyzer is 1.07 , which are impedance mismatch, so the uncertainty component caused by the receive end is:

$$
U_{V S W R}^{T}=0.027
$$

4) Impedance mismatch of Signal source and antenna: In the frequency band of $200 \mathrm{MHz}-1000 \mathrm{MHz}$, VSWR of antenna (connected with $6 \mathrm{~dB}$ attenuator) is 1.2 and that of signal generator is 1.5 , which are impedance mismatch, so the uncertainty component caused by the transmitting end is:

$$
U_{V S W R}^{T}=0.157
$$

5) Site shortage: Antenna factors can vary within the scope of $\pm 1 \mathrm{~dB}$ due to mutual coupling with the ground plane. In every frequency band, we can look up table and get the maximum uncertainty value:

$$
U^{\text {SITE }}=0.307 \mathrm{~dB}
$$

6) Repeatability of system: Measure NSA (unit: $\mathrm{dB} \mu \mathrm{V}$ ) for 10 times in the frequency point $100 \mathrm{MHz}$ by using Log Periodic Antenna (Type: HK223, No: 100183). The measured data are: $25.1,24.3,24.6,24.1,24.2,25.3,24.2,24.1,25.3$, $24.6,24.1$.

$$
U^{\text {SYSTEM }}=1
$$

7) Change of measurement distance: We can find value from the Uncertainty calculation worksheet (Table 3):

$$
U^{L}=0.1 \mathrm{~m}(r=3 \mathrm{~m})
$$

Now we can get the AF combined uncertainty of Log Periodic Antenna:

$$
u=\sqrt{0.173^{2}+0.029^{2}+0.01^{2}+0.055^{2}+0.221^{2}+0.5^{2}+0.084^{2}}=1.08 \mathrm{~dB}
$$


In the end, we get $\mathrm{AF}$ expanded uncertainty of Log Periodic Antenna:

$$
U_{\text {rel }}=2 \times u_{\text {crel }}\left(\delta_{P}\right)=2.16 \mathrm{~dB} \approx 2.2 \mathrm{~dB}
$$

\section{Comparison and Analyzation}

To same Log Periodic Antenna measured, we choose two data measured by SIMT and NIM respectively, which have maximum difference in same frequency point. As discussed above, we trace the standard antennas to NIM, which is the highest traceability institutions and has lower uncertainties than SIMT.

Table 4 shows, there exists maximum difference in the $300 \mathrm{MHz}$ frequency point, the AF data is $14.7(\mathrm{~dB} / \mathrm{m})$ measured by SIMT and AF data is $12.6(\mathrm{~dB} / \mathrm{m})$ by NIM. So we get:

$$
\begin{gathered}
\left|y_{1}-y_{2}\right|=2.1 \mathrm{~dB} / \mathrm{m} \\
\sqrt{U_{1}^{2}+U_{2}^{2}}=\sqrt{2.2^{2}+1.8^{2}}=2.84
\end{gathered}
$$

\begin{tabular}{|c|c|c|c|c|c|c|c|}
\hline Source & Type & Designation & $\begin{array}{l}\text { Uncertainty } \\
( \pm)\end{array}$ & Contribution & $\begin{array}{c}\text { Standard } \\
\text { uncertainty }\end{array}$ & $\begin{array}{l}\text { Sensitive } \\
\text { factor }\end{array}$ & $\begin{array}{c}\text { Standard } \\
\text { uncertainty }\end{array}$ \\
\hline $\begin{array}{l}\text { Relative amplitude } \\
\text { accuracy } \\
\text { of Spectrum } \\
\text { analyzer }\end{array}$ & B & $U_{A}^{S A}$ & $0.6 \mathrm{~dB}$ & Rectangular & 0.173 & 0.5 & 0.173 \\
\hline $\begin{array}{l}\text { Signal generator } \\
\text { amplitude stability }\end{array}$ & $\mathrm{B}$ & $U_{A}^{S G}$ & $0.1 \mathrm{~dB}$ & Rectangular & 0.058 & 0.5 & 0.029 \\
\hline $\begin{array}{c}\text { Impedance } \\
\text { mismatch of } \\
\text { Spectrum analyzer } \\
\text { and antenna }\end{array}$ & $\mathrm{B}$ & $U_{V S W R}^{R}$ & $0.027 \mathrm{~dB}$ & U-shaped & 0.019 & 0.5 & 0.01 \\
\hline $\begin{array}{c}\text { Impedance } \\
\text { mismatch of } \\
\text { Signal source and } \\
\text { antenna }\end{array}$ & $\mathrm{B}$ & $U_{V S W R}^{R}$ & 0.157 & U-shaped & 0.111 & 0.5 & 0.055 \\
\hline Site shortage & B & $U^{S I T E}$ & $0.307 \mathrm{~dB}$ & $\begin{array}{c}\mathrm{T} \\
\text { Distribution }\end{array}$ & 0.441 & 0.5 & 0.221 \\
\hline $\begin{array}{c}\text { Repeatability of } \\
\text { system }\end{array}$ & A & $U^{\text {SYSTEM }}$ & 1 & $\begin{array}{c}\text { Sine } \\
\text { distribution }\end{array}$ & 1 & 0.5 & 0.5 \\
\hline $\begin{array}{l}\text { Change of } \\
\text { measurement } \\
\text { distance }\end{array}$ & B & $U^{L}$ & $\begin{array}{c}0.1 \mathrm{~m} \\
(\mathrm{r}=3 \mathrm{~m})\end{array}$ & Rectangular & $\begin{array}{l}0.058 \\
(r=3)\end{array}$ & $4.34 / \mathrm{r}$ & 0.084 \\
\hline \multicolumn{7}{|c|}{ AF combined uncertainty of log-periodic antenna } & 1.08 \\
\hline \multicolumn{7}{|c|}{ AF expanded uncertainty of } & 2.16 \\
\hline
\end{tabular}

Table 3. Uncertainty calculation worksheet of Log Periodic Antenna in the frequency range $200 \mathrm{MHz}-1000 \mathrm{MHz}$.

Table 4. Uncertainty calculation.

\begin{tabular}{ccccc}
\hline \multirow{2}{*}{ Frequency point } & \multicolumn{2}{c}{ SIMT } & \multicolumn{2}{c}{ NIM } \\
\cline { 2 - 5 } & $\mathrm{AF}$ & Uncertainty & $\mathrm{AF}$ & Uncertainty \\
\hline 300 & 14.7 & 2.2 & 12.6 & 1.8 \\
\hline
\end{tabular}


The results above show that:

$$
\left|y_{1}-y_{2}\right|<\sqrt{U_{1}^{2}+U_{2}^{2}}
$$

So, the conclusion is that measured results on OATS by SIMT meet the requirements in all frequency points.

\section{Conclusion}

This paper reviews aspects of the standard site method in the American National Standards Institute's ANSI C63.5 frequency band of $30 \mathrm{MHz}$ to $1000 \mathrm{MHz}$ is which calibrated using the standard method on OATS. Then it analyzes the issues affecting the measurement uncertainty and evaluates the expanded uncertainty of log-periodic antenna. In the end, it compares the data measured by SIMT and NIM, and verifies that our AF calibration method satisfies requirement.

\section{References}

[1] ANSI C63.5 (2004) American National Standard for Electromagnetic Compatibility-Radiated Emission Measurements in Electromagnetic Interference (EMI) Control-Calibration of Antennas ( $9 \mathrm{kHz}$ to $40 \mathrm{GHz}$ ).

[2] ANSI C63.7 (2005) American National Standard Guide for Construction of OpenArea Test Sites for Performing Radiated Emission Measurements.

[3] CISPR 16-1-4 (2003) Specification for Radio Disturbance and Immunity Measuring Apparatus and Methods-Part 1-4: Radio Disturbance and Immunity Measuring Apparatus-Ancillary Equipment-Radiated Disturbances.

[4] CISPR 16-1-5 (2006) Antenna Calibration.

[5] CISPR 16-1-6 (2008) Standard for the Calibration of Antennas Used for Radiated Emission Measurements.

[6] Smith, A.A. (1982) Standard-Site Method for Determining Antenna Factors. IEEE Transactions on Electromagnetic Compatibility, EMC-24, 316-322. https://doi.org/10.1109/TEMC.1982.304042

[7] ISO/IEC Guide 98-3 (2008) Uncertainty of Measurement-Part 3: Guide to the Expression of Uncertainty in Measurement.

\section{Submit or recommend next manuscript to SCIRP and we will provide best} service for you:

Accepting pre-submission inquiries through Email, Facebook, LinkedIn, Twitter, etc. A wide selection of journals (inclusive of 9 subjects, more than 200 journals)

Providing 24-hour high-quality service

User-friendly online submission system

Fair and swift peer-review system

Efficient typesetting and proofreading procedure

Display of the result of downloads and visits, as well as the number of cited articles

Maximum dissemination of your research work

Submit your manuscript at: http://papersubmission.scirp.org/

Orcontact ijcns@scirp.org 